\title{
O espaço público na dinâmica da paisagem da Praça Morena Bela da cidade de Serrinha-BA
}

Fernando de Souza Nunes*

* Licenciado em Geografia pela Universidade do Estado da Bahia - UNEB e estudante do curso de Especialização em Dinâmica Territorial e Socioambiental do Espaço Baiano pela UEFS Universidade Estadual de Feira de Santana.

\section{Palavras-chave:}

Paisagem; Espaço Público; Praça; Apropriação.

Key-words:

Landscape; Public Space; Square; Appropriation.

\footnotetext{
Abstract: In spite of the structural transformations, storms and functional of the public space, the square represents a privileged space of the citizen playing not only a gathering action and yes, of you vary manifestations where the people, use, they adapt and they link. Therefore, the object of study of the present research is the Morena Bela of the city of Serrinha, Bahia, Brazil, whose category conceptual landscape is used to accomplish a geographical reading of the same, in the perspective of the public space. The study of case of the Morena Bela Square is approached starting from the analytical cutting of 1950 to the current days. However the research had as problem: to what extent is the Morena Bela Square configured how a public space in the city of Serrinha? And as general objective to analyze the use and the appropriation of the Morena Bela Square for their several social agents and if the same is configured as public space. It was used as methodology the inductive for treating of a study of case of the Morena Bela Square. This work is a qualitative and quantitative study rescuing the method qualifying, historical and the cartographic statistical. among other results, it is punctuated: the Morena Bela Square is public, however, you/he/she goes by deep changes in his/her landscape due to social and economical dynamics of the society. She meets in advanced process of privatization due to his/her use for the social agents' parts.
} 


\section{Introdução}

O uso e a apropriação das praças, ao longo das últimas décadas têm mudado significativamente em todo o Brasil. Na cidade de Serrinha, existem muitas praças; no entanto, a Praça Astrogilda Paiva Guimarães, mais conhecida como Praça Morena Bela, localizada especificamente no bairro do Ginásio, é o objeto de estudo da presente pesquisa, onde a categoria conceitual paisagem (reveladora dos diferentes usos e apropriações da praça), foi utilizada para operacionalizar uma leitura geográfica da mesma, na perspectiva do espaço público.

Na paisagem da praça, no entorno, não há Igreja Católica, sede da prefeitura ou fórum, porém, nesta mesma localidade foi implantada o primeiro Ginásio Regional do Nordeste no interior do Estado. Esse diferencial motivou a construção da presente pesquisa, além de sua representatividade para a população da cidade onde está inserida.

O estudo de caso da Praça Morena Bela é um recorte analítico de meados da década de 1950 até 0 ano de 2010, devido à implantação do Colégio Ginasial, o que representa um marco histórico e geográfico para a cidade. Nesse contexto, a referida pesquisa tem como problema: até que ponto a Praça Morena Bela se configura como um espaço público na cidade de Serrinha? Esta pesquisa tem como objetivos gerais analisar o uso e a apropriação da praça Morena Bela pelos seus diversos agentes sociais e verificar se a mesma se configura como espaço público.

A metodologia para atingir os objetivos propostos da referida pesquisa tem como método de abordagem um estudo indutivo e qualitativo, por se tratar de um estudo de caso do espaço da Praça Morena Bela.

Este trabalho justifica-se pelo número reduzido de pesquisas acerca dessa praça e, principalmente, de espaços públicos de fato como palco e cenário da ação, mobilização e articulação da sociedade e do cidadão percebidos pela paisagem geográfica.

\section{Paisagem}

Na geografia, discussão sobre paisagem é antiga e desde o século XIX, vem sendo discutida para se entender as relações sociais e naturais em um determinado espaço, Schier (2003, p. 80)

Por outro lado, a paisagem, enquanto categoria de analise da Geografia, abrange o maior número de funções devido à complexidade da vida social conforme o objeto a ser estudado ou 0 olhar do geógrafo. Aproximando-se da realidade vivida pela maioria das pessoas que têm na paisagem uma mera vista ou visão de um lugar.

A paisagem é o conjunto de objetos que nosso corpo alcança e identifica. 0 jardim, a rua, o conjunto de casas que temos à nossa frente, como simples pedestres. Uma fração mais extensa de espaço, que a nossa vista alcança do alto de um edifício. $O$ que vemos de um avião que voa a mil metros de altura é uma paisagem, como a que apreendemos numa extensão ainda mais vasta, quando de uma altura maior. A paisagem é o nosso horizonte, estejamos onde estivermos (SANTOS, 2008, p. 84).

Geografia Ensino \& Pesquisa, v. 16, n. 3 p. 49 - 62, set./dez. 2012

O espaço público na dinâmica da paisagem da praça Morena Bela da cidade de Serrinha-BA

50

ISSN 2236-4994
Tendo em vista o entendimento de que a paisagem pode ser vista como todo o horizonte que se vê, o referido autor traduz a forma como o ser humano entende a paisagem a partir dos sentidos. Por isso, a visão que se tem da paisagem revela uma subjetividade própria do indivíduo na sua forma de produzir espaço.

Tal pensamento de Milton Santos é condizente com a realidade, porque cores, odores, sons, dentre outros, são vistos de forma individual pelo cidadão que se apropria da praça. Ao mesmo 
tempo em que se observa a paisagem de uma perspectiva, ela traduz o resultado consequente da sua funcionalidade, forma e estrutura num espaço-tempo processual.

As paisagens vão surgindo na medida em que os homens vão vivendo e produzindo as suas vidas. As paisagens locais, na maioria das vezes, fazem parte das vidas particulares das pessoas que vivem no lugar. Portanto, agrega-se a essas paisagens, além de um olhar afetivo, um sentido estético capaz de marcar no imaginário das pessoas a identidade do lugar. Existem paisagens que são artificiais, quer dizer, transformadas pelo homem, e as naturais, que não sofreram interferência do homem.

A paisagem não se cria de uma só vez, mas por acréscimos, substituições; a lógica pela qual se fez um objeto no passado era a lógica da produção daquele momento. Uma paisagem é uma escrita sobre a outra, é um conjunto de objetos que têm idades diferentes, é uma herança de muitos diferentes momentos. (...) Assim, a paisagem é uma herança de muitos momentos, já passados, o que levou Lênin a dizer que a grande cidade é uma herança do capitalismo e veio para ficar, devendo os planejadores do futuro levar em conta essa realidade (SANTOS, 2008, p. 73).

Entre outras palavras, pode-se afirmar que a paisagem, por meio da ação processual humana, é resultado de transformações de diversos momentos cujo objeto pode ser naturalizado pelo tempo atual e ser na verdade característico de um tempo passado.

Vale salientar que, tendo em vista a paisagem ser uma escrita sobre outro(s) conjunto(s) de objetos diferentes, herdados do processo de construção material de objetos corporificado e social, ela não é algo estático, sem interação com o meio e o contexto global. Mas para chegar a este pensamento. Faz-se necessário, uma distinção entre trabalho vivo e trabalho morto pois:

A paisagem não é dada para todo o sempre, é objeto de mudanças. É um resultado de adições sucessivas. É uma espécie de marca da história do trabalho, das técnicas. Por isso ela própria é parcialmente trabalho morto, porque é formada por elementos naturais e artificiais. A natureza natural não é trabalho. Já o seu oposto, a natureza artificial, resulta de trabalho vivo sobre trabalho morto. (...) As casas, a rua, os rios canalizados, o metrô etc. são resultados do trabalho corporificado em objetos culturais. Não faz mal repetir: suscetível a mudanças irregulares ao longo do tempo, a paisagem é um conjunto de formas heterogêneas, de idades diferentes, pedaços de tempos históricos representativos das diversas maneiras de produzir as coisas, de construir o espaço (SANTOS, 2008, p. 74-75).

Esclarecido a diferença clara entre trabalho vivo e morte na compreensão daquilo que resulta a paisagem, a construção e produção da mesma, dentro da dinâmica do tempo no espaço, seja ele lento ou rápido, é fruto das articulações políticas, econômica, culturais e processuais no contexto urbano segundo Santos (2008). Tal afirmação norteia a presente pesquisa sob o olhar da técnica na construção material do espaço, visto que:

Na ciência geografia, a paisagem é um conjunto de estruturas socioespaciais de um determinado local, que permite uma espécie de interatividades entre si e o homem, que a "percebe" por meio de seus sentidos, principalmente a visão. (...) É comum que as pessoas considerem como paisagem apenas uma soma de diversos elementos naturais, como montanha, rios e florestas, mas há as que são formadas pela intervenção humana, responsável pela criação de edificações, plantações, casas, pontes, ruas e afins (MACHADO, 2008 p. 54).

Dessa forma, pode-se classificar a paisagem em duas formas: natural - em que os elementos naturais encontram-se em maior destaque nas abordagens, tendo em vista dificilmente encontrarem-se ambientes ditos naturais que não tenham passado pela interferência do homens,

Geografia Ensino \& Pesquisa, v. 16, n.3 p. $49-62$, set./dez. 2012

Nunes, F. S.

ISSN 2236-4994 | 51 
como um planalto onde se vê no topo uma torre de celular e a paisagem; e artificial - como a cidade, dentre outros, Santos (2008).

A paisagem é um conjunto heterogêneo de formas naturais e artificiais; é formada por frações de ambas, seja quanto ao tamanho, volume, cor, utilidade, ou por qualquer outro critério. A paisagem é sempre heterogênea. A vida em sociedade supõe uma multiplicidade de funções, e quanto maior o número destas, maior a diversidade de formas e de atores. Quanto mais complexa a vida social, tanto mais nos distanciamos de um mundo natural e nos endereçamos a um mundo artificial (SANTOS, 2008, p. 71).

Todavia, para o senso comum, a paisagem artificial pode ser considerada como natural, não no sentido em que a palavra está conceituada, mas na sua repetição no espaço e no seu convívio costumeiro com o tipo da paisagem.

Portanto, a paisagem, dentro de sua dinamicidade temporal e espacial, apresenta-se num estágio definido no início de sua formação por ser algo de fácil destaque na natureza, no entanto, quando essa natureza passa a ser transformada ao longo do tempo resultando numa paisagem mais artificial, ela passa a ser incorporada e percebida pelas pessoas como algo "normal" ou "natural" no convívio socioespacial.

\section{Espaço público}

O espaço público é um conceito polissêmico, surgiu na teoria política clássica e foi incorporada ao inconsciente coletivo das sociedade na Antiga Grécia no qual "exerciam sua capacidade de participação crítica na gestão dos assuntos comuns, sob o princípio da deliberação; um espaço que se opunha, portanto, ao espaço privado regido pela dominação do poder" (DUPAS, 2005, p. 37-38).

Este mesmo espaço se contrapõe ao privado, ao dominado pelo poder. E, com o passar dos séculos, o espaço público - especificamente as praças - torna-se dominado pelas organizações de estratégias autônomas, os quais usam do seu poder de influência para que o espaço público seja, na verdade, algo voltado aos interesses de uma classe econômica e politicamente forte.

$O$ adjetivo público traduz-se não somente numa mera acessibilidade generalizada e irrestrita a todos, num espaço "aberto" de uso coletivo, Serpa (2007, p. 16), mas, se o desafio é pensar espaço público de modo amplo, deve-se pensar que a esfera pública tem como uma de suas principais funcionalidades permitir que os sujeitos sociais que dela se apropriam saibam conviver de modo coletivo, permitindo e respeitando o contato com o outro, visto que

A esfera pública não se restringe apenas aos espaços concretos de circulação e repartição de fluxos, nem aos espaços materiais de consumo, lazer e diversão. É a esfera pública que nos reúne na companhia uns dos outros, mas é ela também que evita que colidamos uns com os outros. 0 difícil em suportar a sociedade de massas não é tanto a quantidade de gente que ela abarca, mas o fato de que 0 mundo perdeu literalmente a força de juntar essa imensa quantidade de indivíduos, relacionando-se e separando-os dialeticamente (SERPA: 2008, p. 409).

Geografia Ensino \& Pesquisa, v. 16, n. 3 p. 49 - 62, set./dez. 2012

O espaço público na dinâmica da paisagem da praça Morena Bela da cidade de Serrinha-BA

521

ISSN 2236-4994
Apesar de os espaços públicos estarem diminuindo ou se transformando em espaços privados, provavelmente isso reflete a mudança de valores na sociedade e sua capacidade de percepção e conscientização política e social do que é viver em um espaço onde todos, coletivamente, têm o direito de usufruir.

Percebe-se que o espaço público evita que as pessoas venham a colidir umas com as outras no sentido de desrespeitar o direito que o outro tem de estar na praça, cuja capacidade é de agregar indivíduos que se relacionam e o fato de não viver isolado e separado reforça a noção de cidadania. 
"territorialização do espaço", cujos usuários privatiza-o através de ereção de barreiras simbólicas, por vezes invisíveis. 0 espaço público transforma-se, portanto, em uma justaposição de espaços privatizados; ele não é partilhado, mas, sobretudo, dividido entre os diferentes grupos.

Se a apropriação coletiva de indivíduos não é suficiente para legitimar o espaço público, a territorialização do espaço (fruto em muitos casos da ideologia capitalista de tornar tudo consumível) torna-o um bem de uso privado e dividido por parte dos diferentes grupos tornando a acessibilidade controlada simbolicamente, havendo estranhamento e disputa de controle por parte dos grupos sociais. O espaço deixa de ser uma articulação da ação política para ser o palco do privado, segundo a lógica do capital.

Falta interação entre esses territórios, percebidos (e utilizados) como uma maneira de neutralizar o "outro" em um espaço que é acessivel a todos. Os usuários do espaço contribuem assim para amplificação da esfera privada no espaço público, fazendo emergir uma sorte de estranhamento mútuo de territórios privados, expostos, no entanto, a uma visibilidade completa. (JOSEPH, 1998 apud SERPA, 2008, p. 410).

Por isso faz-se necessário entender e distinguir claramente o que é público e privado, posto que o elemento que caracteriza o espaço - ou especificamente a praça - é justamente a sua finalidade:

Diferença entre público e privado: o substantivo público, neste texto, é entendido como todo bem ou serviço que serve para o uso de todos. Já o privado, equivale a todo bem ou serviço pertencente ou prestado por uma pessoa ou entidade (empresa, associação, etc.) cujos resultados interessam essencialmente a essa pessoa ou entidade (SPÓSITO, 2004, p. 34).

Levando-se em conta o dever de diferenciar conceitualmente espaço público e privado para o entendimento de um bem de uso coletivo sem perder de vista as contradições da produção e apropriação desse espaço, Serpa (2007) entende

o espaço público como o espaço da ação política, ou ao menos, da possibilidade da ação política na contemporaneidade, como mercadoria para o consumo de poucos, dentro da lógica de reprodução e reprodução do sistema capitalista na escala mundial. Ou seja, ainda que seja público, poucos se beneficiam desse espaço teoricamente comum a todos (SERPA,2007, p. 9).

Em outros trabalhos, Serpa atesta que essa apropriação, produção, acesso e consumo, na lógica capitalista, são desiguais:

Essa característica fundamental contrasta, nas cidades contemporâneas, com o processo de incorporação dos espaços públicos urbanos como mercadorias para o consumo de poucos, dentro da lógica de produção e reprodução do sistema capitalista na escala mundial. Ou seja, ainda que sejam adjetivados como públicos, poucos se beneficiam desses espaços teoricamente comuns a todos (SERPA, 2008, p. 405).

A praça é reflexo a produção desigual do espaço geográfico onde poucos se beneficiam dele. Apesar de serem público, poucos se beneficiam desses espaços devido a diversas estratégias de influência e barganha junto aos grupos que controlam o poder local.

Geografia Ensino \& Pesquisa, v. 16, n.3 p. 49 - 62, set./dez. 2012

Nunes, F. S. 
O que significa o termo praça, não somente no sentido teórico como na prática? 0 dicionário online Priberam (2010), declara que praça é um lugar público, largo, cercado de edifícios. Ela pode designar outras conotações como mercado, feira, leilão e pode ser também praça de armas e praça de guerra, no sentido de fazer referência à participação de brasileiros ou alguém ilustre numa guerra.

Seja como for, a praça apresenta funções em comum, como proporcionar convivência e recreação para os agentes que dela se apropriam ou à utilizam. Vale ressaltar que a noção de praça varia de população para população ou conforme a cultura de cada povo ou lugar.

O sugimento da palavra praça, é antigo, e de origem latina, igual a pláteia (caminho largo, rua espaçosa e larga), considerada por muitos como um espaço democrático, coletivo. Os usuários são anônimos, indeterminados e os bens são coletivamente utilizados por todos os seus membros:

[...] as cidades dos povos ameríndios ou latinoamericanos - os Maias, já delineavam uma praça de caráter muito simbólico que funcional, habitada por deuses ou quem os representasse (imperador, corte, sacerdotes), sendo ponto de encontro do povo apenas para as cerimônias religiosas. (PINHEIRO, 1999, p.7).

Para os gregos, havia a ágora, que se localizava no centro das suas cidades, e que servia para 0 encontro dos cidadãos ao ar livre. Na ágora realizavam-se atividades como reunião das assembléias políticas e dos tribunais e lugar de ensino dialogal dos filósofos e não de serviços religiosos que estavam resevados a arcópoles:

Aideia de que as cidades têm uma esfera pública, pertencem à coletividade e por ela
usada, e uma esfera privada, cuja posse e manutenção respondem aos interesses
de um ou mais indivíduos específicos, é bastante antiga, definindo-se plenamente
na cultura grega durante a Antiguidade. Para os gregos, ágora era o espaço que,
na polis, representava o espírito público desejado pela coletividade. Era o espaço
de exercício da cidadania. Nesse período, limite entre os espaços públicos e os
privados era bem claro (OLIVEIRA; COELHO; CORREIA, 2008, p. 436).

Dessa forma, a cultura ocidental herdou, através da Ágora, a noção de que a praça além de ser pública, é algo coletivo. Também na antiguidade, surgiu a noção de privado enquanto posse subordinado a interesses de um ou mais grupos.

Se na ágora grega traduzia aquilo que seria o exercício da cidadania, uma democracia direta, um lugar para a discussão do bem em comum (política) entre aqueles que poderiam se chamar de cidadãos.

$\mathrm{Na}$ Roma Antiga, o Fórum romano representava em si mesmo a monumentalidade do Estado, sendo que o indivíduo que por ele passasse estava espacialmente subordinado aos enormes prédios públicos que o configuravam, diferenciando-se da Ágora na medida em que "o espaço de discussão não mais era a praça pública, aberta, mas o espaço fechado dos edifícios, cuja penetração era mais restrita" de acordo com (PINHEIRO, 1999, p.8).

Com a influência da religião Católica nos valores e costumes da sociedade durante a Idade Média, as praças barrocas obedeciam ao espírito contra-reformista: Elas se aglutinavam em torno das catedrais que se encontravam fora dos limites da cidade, pois, as praças centrais das cidades

Geografia Ensino \& Pesquisa, v. 16, n. 3 p. 49 - 62, set./dez. 2012

O espaço público na dinâmica da paisagem da praça Morena Bela da cidade de Serrinha-BA

54

ISSN 2236-4994 medievais eram consideradas de caráter profano: são revelações arquitetônicas das origens burguesas da cidade, em geral dominadas pelo seu principal palácio governamental, tratadas de forma paisagística.

A partir de um determinado contexto, a típica praça das cidades brasileiras se caracteriza por ser bastante ocupada por vegetação e arborização, estando intimamente ligada ao ajardinamento, ao verde e estruturada em largos. A Praça costuma possuir equipamentos recreativos e contemplativos: como playgrounds, recantos para estar, equipamentos para ginástica e cooper, bancos, mesas, etc. 
Sua configuração está associado ao desenvolvimento da cidade como fator decisivo dos centros urbanos e das sociedades capitalistas.

Portanto, não deve existir exclusividades ou privilégios na sua utilização, motivo pelo qual a praça adiquire um carater comunitário. Em outras palavras, praça é um lugar público, grande, largo, em alguns casos rodeada por edifícios, útil para embelezar uma cidade ou bairro, e onde melhor circula 0 ar devido à presença das árvores.

Novos modelos mundiais surgem nas sociedade capitalistas a exemplo dos shoppings centeres, lan house, cafés, restaurantes, bares e praças de alimentação. Com isso, o espaço público passa a ser entendido como espaço de consumo em detrimento do consumo do espaço. $\mathrm{E}$ estes mesmos espaços não podem ser considerados como espaços públicos e sim, espaços de uso coletivo conforme Carlos (2007).

\section{Processos espaciais antecedentes da Praça Morena Bela}

Por meio de entrevista realizada em 01/10/2010 com o Sr. Edmundo Bacelar - Presidente do Museu Pró Memória de Serrinha -, foi possível constatar que a área onde atualmente se localiza o Colégio Estadual Rubem Nogueira e a Praça Morena Bela era uma fazenda. No entanto, não há registros de quem era o proprietário dessas terras.

Dos poucos registros de que se tem conhecimento, em meados da década de 1920, o terreno passou a ser propriedade do Governo do Estado por meio da Secretaria de Agricultura dando início a uma nova função àquele espaço, que modificou a paisagem local com a implantação do Projeto de Sericicultura ou Bicho-da-Seda - criada por decreto de n. ${ }^{\circ} .670$, no dia 13 de agosto de 1935 e a construção ocorreu entre os anos de 1935 a 1937, concluída no início do ano de 1938 conforme (PINHEIRO, 1999, p. 13).

Após a construção da Estação de Sericicultura "a seca atingiu a cidade na década de 1930 e fez com que o prédio fosse ocupado pelo serviço de cereais e leguminosas" e em 1952, cedido a Secretaria Estadual de Educação para a implantação do Ginásio Regional do Nordeste (PINHEIRO, 1999, p. 13).

A Figura 1 mostra o Ginásio Regional do Nordeste após a sua inauguração, no ano de 1960. Essa nova função permite o surgimento de um conjunto de outras formas como as inúmeras casas residenciais e, mais tarde, comerciais.

Figura 1 - Colégio Ginasial após a inauguração, na década de 1960, hoje Colégio Estadual Rubem Nogueira - Serrinha

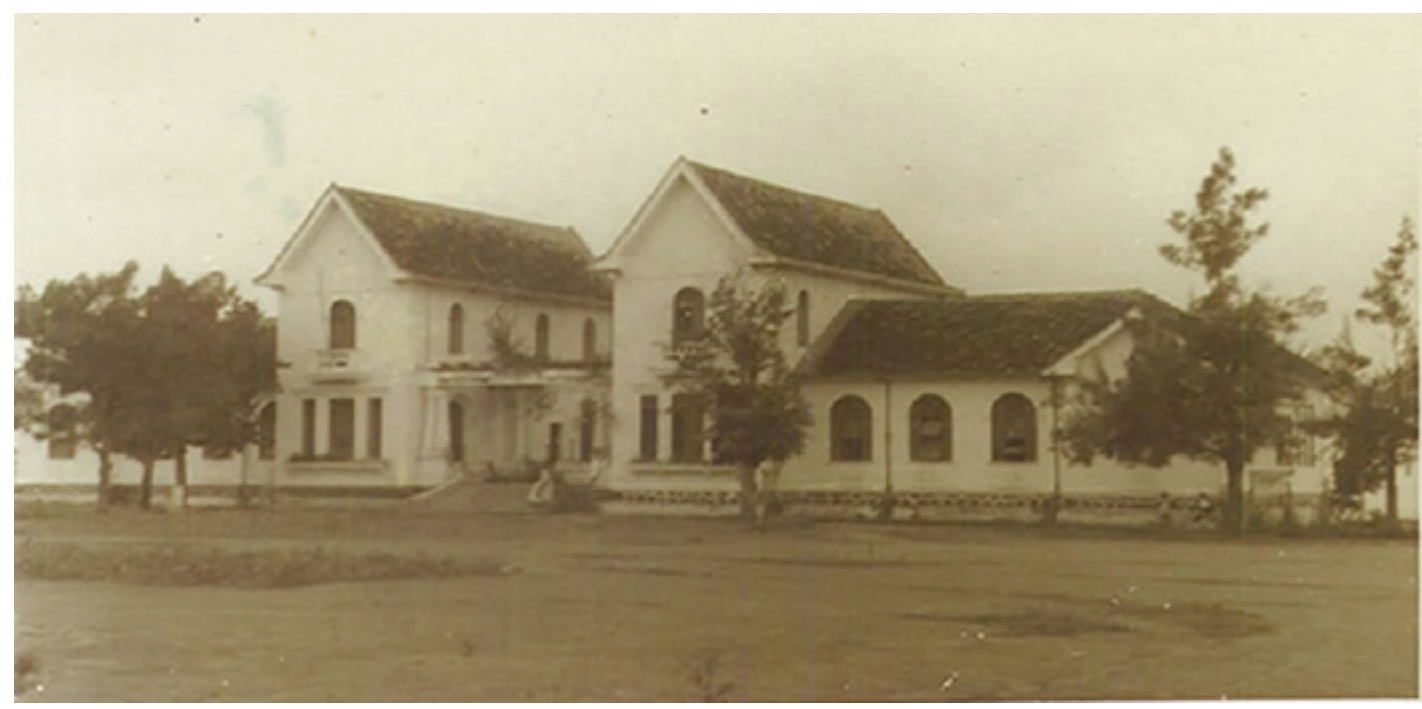

Geografia Ensino \& Pesquisa, v. 16, n.3 p. 49 - 62, set./dez. 2012 
Nesse contexto, o processo de interiorização da educação no interior do estado expressava todo um conflito entre as elites regionais do estado que denota relações de poder conforme Castro; et.al (2005).

\section{Processos espaciais antecedentes da Praça Morena Bela}

Esta discussão aborda o surgimento da Praça Morena Bela como um marco da paisagem da mesma para o surgimento da praça e as implicações da gestão de alguns ex-prefeitos como: Antonio Josevaldo da Silva Lima no ato da criação, Paulino Alexandre Santana (Popó) e Tânia de Freitas Mota Lomes.

Antes da construção da praça em frente ao Colégio Ginasial (Figura 1), existia um grande largo com um solo de textura vermelha chamado pelos serrinhenses de "selão". Nele, os estudantes, até meados da década de 1980, jogavam bola ou praticavam alguma atividade esportiva desenvolvida pelos professores do Colégio (Figura 2), e no período de verão, a grande queixa dos moradores e frequentadores era a poeira vinda do largo; e no inverno, o maior problema para estudantes e professores era a lama.

Figura 2 - Colégio Estadual Rubem Nogueira na década de 1980, antes da construção da Praça Morena Bela na cidade de Serrinha

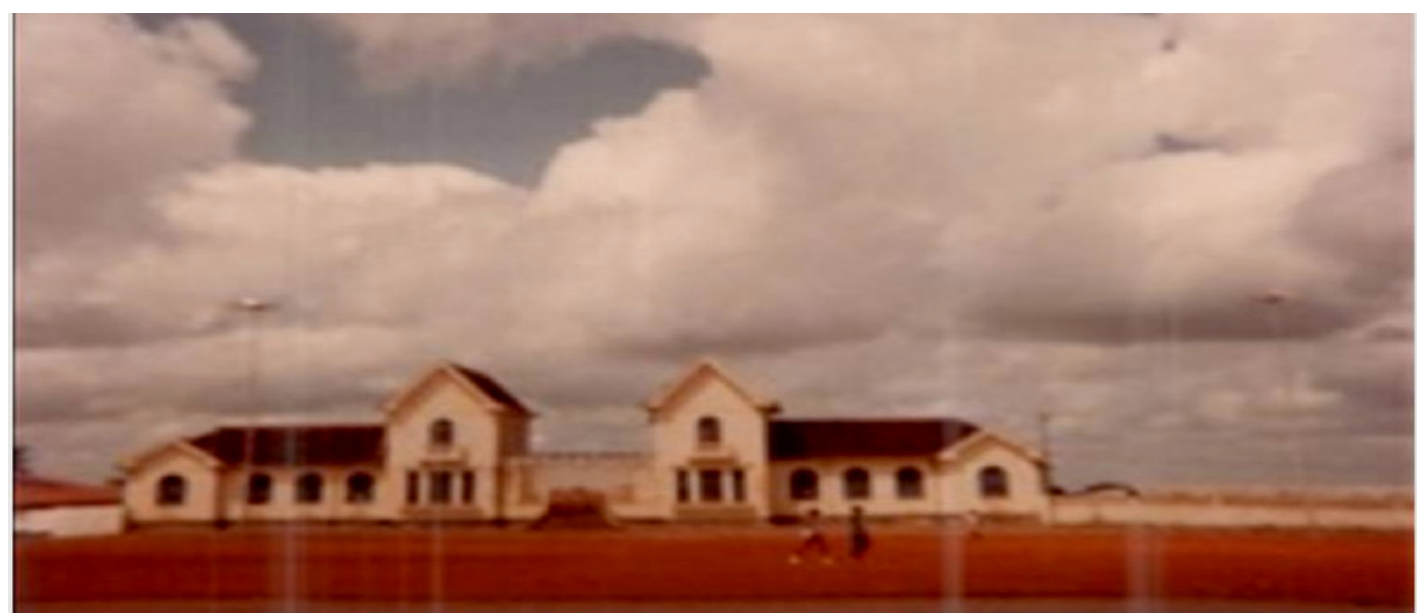

Fonte: Museu Pró Memória de Serrinha, 1980

O prefeito Josevaldo Lima, inaugurou a Praça Astrogilda Paiva Guimarães no dia 04 de novembro de 1899 (seu aniversário), aonde funcionava o largo do Ginásio, mais conhecida como Morena Bela.

Atualmente, as ruas que dão acesso a Praça Morena Bela são: Rua Abdon Costa, Avenida Luiz Viana Filho, Rua André Negreiros Falcão (ex-deputado estadual e primeiro prefeito de Serrinha), Avenida do Imperador, Rua Manoel Chileno, Rua Reginaldo Ribeiro e Avenida Mário Andreazza. 
Figura 3 - Mapa digital da Praça Morena Bela da cidade de Serrinha-BA, ao centro

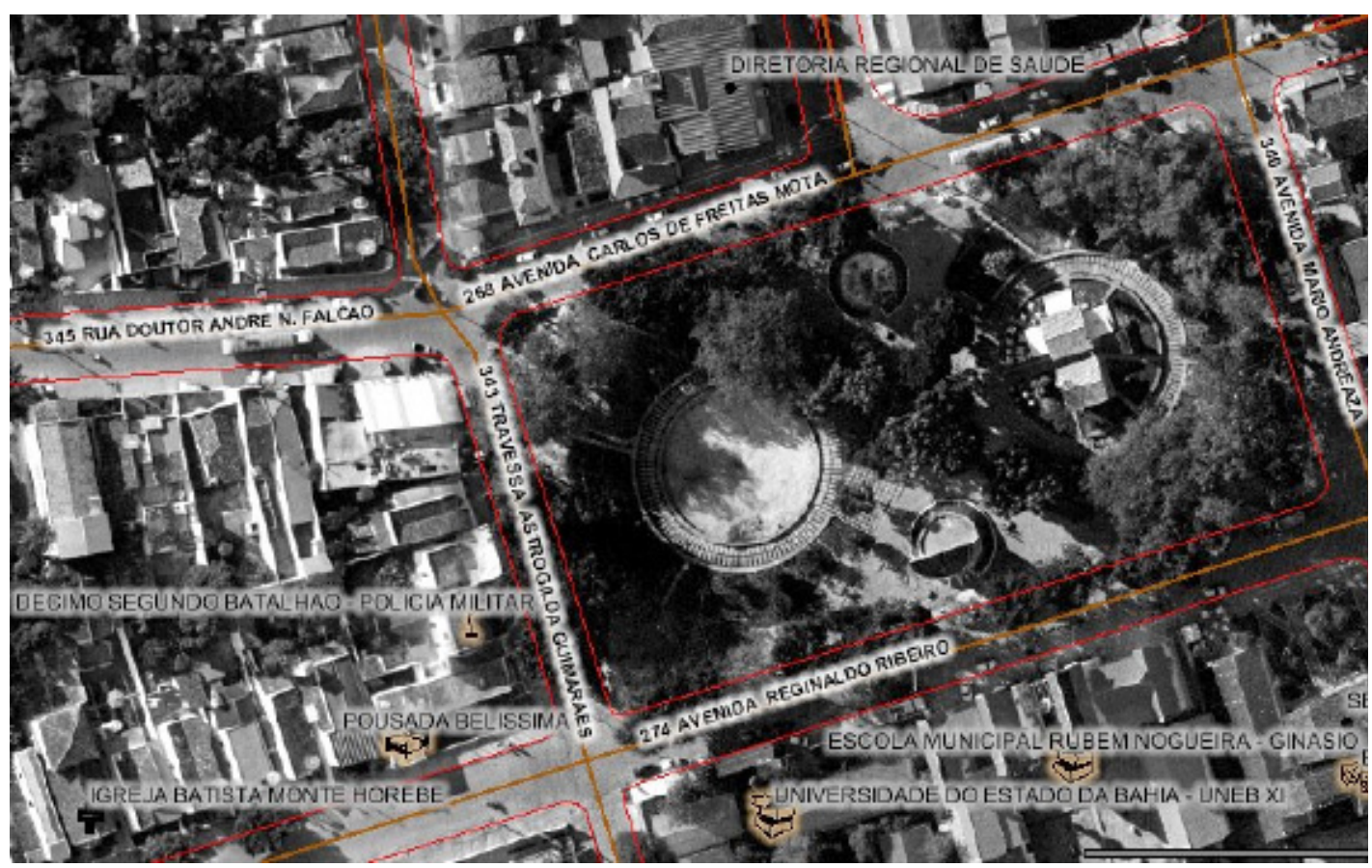

Fonte: Companhia de Desenvolvimento Urbano do Estado da Bahia - CONDER, 2012

Em entrevista, Josevaldo Lima justificou que a inauguração da praça no dia do seu aniversário se deu num período eleitoral:

por conta do meu sucessor, Paulino Alexandre Santana (Popó), cair nas pesquisas de intenção de voto devido ao consumo diário e exacerbado de bebida alcoólica e descrédito com a população. Como a praça estava há mais de quatro anos em reforma e para mostrar que o meu sucessor era confiável, montei uma equipe para assessorar a administração de Paulino e mostrar que ele estaria acompanhado de minha pessoa, demonstrando à população a minha influência. De fato, pude perceber que, com a inauguração da praça após o dia 04/11/1988, nós estávamos ganhando 300 votos por dia. Com investimento em publicidade da praça, Serrinha começou a atrair gente de outras cidades, devido à praça ser o maior logradouro da região feita com verba pública dos cofres do município. $E$ no final, Popó foi reeleito como desejávamos (LIMA, 2010).

A praça foi batizada de Astrogilda Paiva Guimarães por se tratar de uma homenagem à professora de Português, uma das primeiras professoras a comporem o quadro de docentes do antigo Colégio Regional do Nordeste (Colégio Estadual Rubem Nogueira) criadas em 19 de março de 1952 (FRANCO, 2008, p. 403) e da Escola Normal de Serrinha instalada em 17 de março de 1956 (FRANCO, 2008 p. 407) respectivamente o primeiro colégio ginasial e técnico normal do interior da Bahia.

Todavia, por meio da pesquisa documental, constatou-se que o prevalecimento do nome "Morena Bela" ocorreu devido a uma homenagem feita por parte dos arquitetos e planejadores às morenas de Serrinha como "as mais belas e bonitas de toda a região" (PINHEIRO, 1999, p.16).

Após a construção da Praça Morena Bela, os jovens elegeram-na como um novo ponto de encontro dos seus pares, visto que, antes, essa aglomeração acontecia na Praça Luiz Nogueira, localizada no centro da cidade. Porém, moradores relataram em entrevista que o prefeito da época, Josevaldo Lima, deixou essa última praça sem iluminação por muito tempo para valorizar a recéminaugurada Praça Morena Bela.

Geografia Ensino \& Pesquisa, v. 16, n.3 p. 49 - 62, set./dez. 2012

Nunes, F. S.

ISSN 2236-4994 57 
A construção da praça, embora reforçado o discurso político com verdadeiras propagandas eleitoreiras aos olhos das classes mais populares que se vislumbraram diante da obra, contribuindo, conforme entrevista com o Sr. Josevaldo Lima, reeleger Popó como o seu sucessor nas eleições municipais.

No governo de Paulino Alexandre Santana (Popó), no início da década de 1990, a praça, anos após a sua inauguração, passou por um período de decadência, todavia, devido a uma prática comum a gestores que, ao assumem o posto de prefeito do município com o apoio de Josevaldo Lima, não deu continuidade a algum projeto ou obra que tenha sido realizado em governos passados pertencentes a grupos políticos adversários ou aliados do atual gestor conforme entrevistas realizadas no mês de setembro de 2010.

Notou-se através da paisagem do local que o número de estabelecimentos comerciais em torno da mesma aumentou consideravelmente nos últimos anos influenciando no preço imobiliário dos estabelecimentos localizados no entorno da praça.

No ano de 2008, a ex-prefeita Tânia de Freitas Lomes, que assumiu o governo após dois anos de mandato de Claudionor Ferreira da Silva (Ferreirinha), afastado por motivos de saúde, implementou algumas reformas na praça (Figura 3) alterando ainda mais as características da estrutura do seu projeto inicial e da paisagem.

Foram demolidos a concha acústica para dar maior visibilidade ao prédio do Colégio Estadual Rubem Nogueira, construção de um ponto de alimentação dentro da praça ou quiosque (a fim de favorecer os donos dos traillers que estavam localizados no entorno da praça, cuja presença era questionada pela população e aos frequentadores). Nova iluminação com luz térrea foi colocada para dar destaque às árvores da praça, e foi feito o conserto da fonte luminosa e da casa de bonecas.

Figura 4 - Praça Morena Bela nos dias atuais na cidade de Serrinha - 2010

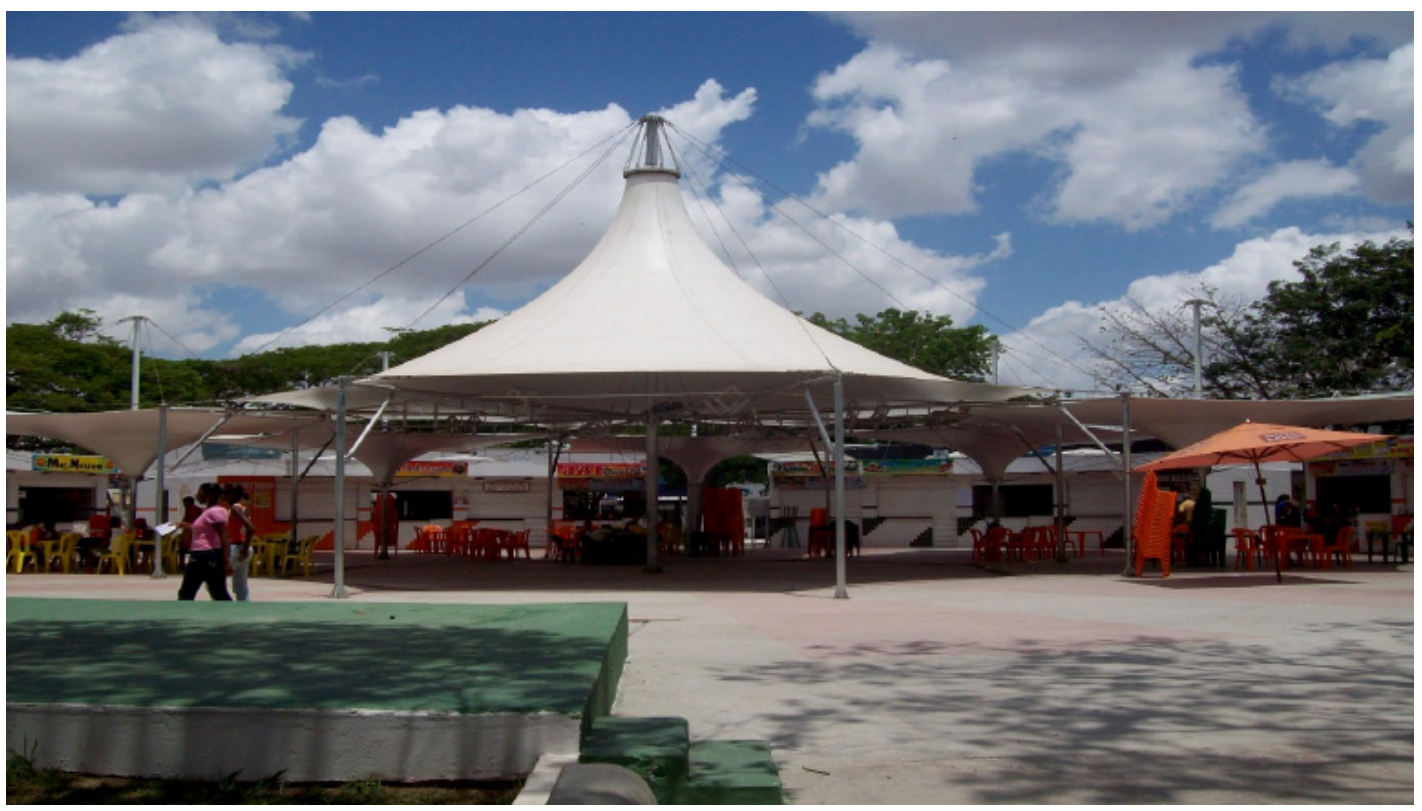

Fonte: Fernando de Souza Nunes, 2010

No caso dos antigos traillers que foram removidos para a construção dos quiosques ou

Geografia Ensino \& Pesquisa, v. 16, n.3 p. 49 - 62, set./dez. 2012

O espaço público na dinâmica da paisagem da praça Morena Bela da cidade de Serrinha-BA boxes na Praça, verificou-se que o poder público municipal por meio do PDDU - Plano Diretor de Desenvolvimento Urbano (2003) - tem a prerrogativa de, por meio dos poderes municipais constituídos, conceder licença de uso de solo e espaço para proprietários e comerciantes locais, não sendo permitida a sua venda e transferência sem autorização dos órgãos que o regulamentem, e por se tratar de um terreno de uso público. 


\section{Avaliação, concepções e percepções dos agentes produtores da Praça Morena Bela}

Levando-se em conta que os agentes sociais do território são agentes produtores e, tendo em vista conhecer na empiria, por meio de conceitos científicos, a definição entre público e privado, partiu-se para a seguinte pergunta: os agentes aceitariam a idéia de privatizar a praça ou transferir a sua administração para o capital privado?

Conforme o Quadro 1, observa-se que na resposta 1, 91\% dos agentes são contrários a proposta de privatizar ou transferir a administração da praça para a iniciativa privada, apresentando como justificativa o fato de ser algo comum a todos; e no resposta 2, 9\% dos entrevistados colocaram-se favoráveis à transferência da administração para melhorar a praça.

Quadro 1 - Opinião dos entrevistados sobre a transferir a administração da Praça Morena Bela para a iniciativa privada -2010

\begin{tabular}{|c|c|}
\hline Síntese das respostas & Frequência \\
\hline $\begin{array}{c}\text { R1 - Não, porque a privatização não permite que todas as pessoas tenham acesso, e sim } \\
\text { somente o grupo ao qual pertence. Não consigo imaginar, ver pessoas que trafegam na } \\
\text { praça tendo que um dia pagar para frequentar a Praça Morena Bela (transeunte). }\end{array}$ & 39 \\
\hline R2 - Para mim, tanto faz; se for para melhorar a praça, ótimo (comerciante). & 4 \\
\hline
\end{tabular}

Fonte: Pesquisa de campo, 2010

Org.: Fernando de Souza Nunes, 2010.

Para se entender a produção do espaço da Praça Morena Bela e sua evolução, na perspectiva da paisagem torna-se necessário interpretar as principais funções e apropriações partindo da empiria, da percepção dos agentes como algo muito mais voltado ao conhecimento por meio dos sentidos do senso comum.

São diversos os usos e apropriações da Praça Morena Bela como um determinado contexto social que resulta nas tarefas desempenhadas por determinadas formas espaciais, as quais cumprem tarefas que se chamam de funcionalidade.

Enquanto a forma é o aspecto visivel do objeto, a função constitui uma tarefa, atividade ou papel a ser desempenhado pelo objeto na dinâmica da estrutura que se refere à maneira pela qual os objetos estão interligados entre si, sendo ela invisível, subjacente à forma.

Mas, para entender melhor as formas de uso e apropriação da Praça Morena Bela, foi perguntado aos entrevistados (Quadro 2) quais os eventos que mais solicitam a praça durante 0 ano. E como resposta, observou-se que os eventos que mais atraem frequentadores é a Vaquejada com $56 \%$ de frequência, seguidos dos festejos natalinos e de final de ano, com $28 \%$ e, por último, as festas juninas, com $16 \%$.

Quadro 2 - Eventos da cidade de Serrinha, que mais solicitam a Praça Morena Bela segundo os agentes sociais -2010

\begin{tabular}{|c|l|c|}
\hline Síntese das respostas & Frequência & Percentual \% \\
\hline Vaquejada & 24 & $56 \%$ \\
\hline Festas natalinas e de final de ano & 12 & $28 \%$ \\
\hline Festas Juninas & 7 & $16 \%$ \\
\hline
\end{tabular}

Fonte: Pesquisa de campo, 2010

Geografia Ensino \& Pesquisa, v. 16, n.3 p. 49 - 62, set./dez. 2012

Nunes, F. S.

Vale salientar que a Vaquejada (inspirada no cotidiano dos vaqueiros que se embreavam pelo mato a procura de bois que fugiam das propriedades rurais e eram capturados somente com 
a ajuda de cavalos), é uma festa popular do município realizada no mês de setembro no bairro de mesmo nome, porém, atraí turistas e a população abastarda que não tem acesso ao local do evento devido ao exorbitante valor do ingresso.

\section{Considerações finais}

Neste item, por meio do processo metodológico para a obtenção dos resultados da presente pesquisa, foi possivel compreender e responder aos problemas, questões norteadoras e objetivos desta pesquisa sobre o espaço público na dinâmica da paisagem da Praça Morena Bela na cidade de Serrinha-BA.

A Praça Morena Bela é uma propriedade pública, porque ela é um bem pertencente ao Poder Municipal que estende o seu uso, consumo e acessibilidade a várias pessoas, servindo a todos, sob o processo de produção que interessa a todas as pessoas. Ela não é a principal praça da cidade, todavia, perpassa por um processo de centralização por causa do seu dinamismo particular percebido na paisagem geográfica possuindo também, forte identidade com os agentes que frequentam a praça revelada como lugar.

Porém, mediante discussão teórica dos conceitos de espaço público e paisagem e praça nos capítulos da pesquisa; analise processual da praça que resulta da atual configuração espacial da paisagem; funcionalidades e percepções do espaço; apesar da praça ser pública, o uso por parte dos agentes sociais e modeladores acaba por ressignificar a noção de público e ela encontra-se em processo avançado de privatização devido ao resultado da apropriação por parte dos comerciantes que, por meio do PDDU, ganharam o direito de ocupar os quiosques dentro do perímetro da praça.

A Praça Morena Bela é usada de múltiplas formas e apresenta-se vinculada ao cotidiano dos estudantes que a frequentam por estarem próximas das escolas para fins de namoro e diversão, dos funcionários públicos que usam para se deslocar para o trabalho, moradores e transeuntes que usam a praça para o lazer familiar e a noite nas diversas sociabilidades como eventos festivos e manifestações culturais que mais solicita a Praça Morena como a vaquejada. Diferente dos comerciantes que se apropriam da praça ao ocupar os quiosques da praça como instrumento de trabalho. Tais exemplos de funcionalidades implicam nas diferentes formas de uso e apropriação vistos na paisagem da Praça Morena Bela.

Ainda na presente pesquisa, a paisagem da Praça Morena Bela é diferente, e ela não se repete no contexto urbano, por ser um espaço aberto para as relações humanas no cotidiano e por ser social sendo importante para a população serrinhense.

A paisagem da Praça Morena Bela mostra uma realidade espacial fruto de vários processos sociais, e sua relação com o espaço é voltado ao uso e apropriação da mesma. Além de ser formada, é um conjunto e resultado heterogêneo de formas naturais e artificiais que vão desde a presença de árvores em torno da mesma até os bares, equipamentos de lazer para crianças, dentre outros, que fazem parte da vida particular de muitas pessoas que vivem no bairro ou na cidade, devido à afetividade presente na memória das pessoas.

Por isso, os conceitos de paisagem e espaço público foram importantes não somente para operacionalizar a presente pesquisa e sim, responder se a Praça Morena Bela de fato é pública ou não e se ela passa por um processo de privatização.

Todavia, com as mudanças ocorridas na praça a fim de atender à lógica do capital e do mercado, o que se chamava de espaço do cidadão vem se tornando o espaço do consumo e 0 consumo do espaço, porque o sujeito deixa de ser cidadão ao se apropriar da praça para ser consumidor do espaço.

Conforme vista da paisagem da Praça Morena Bela, as ações de reforma da praça e a 
alocar os comerciantes que se apropriavam de locais indevidos ao redor da praça sem autorização da Prefeitura demonstram que a praça se tornou um mero espaço de consumo.

Essas mudanças na paisagem ao longo do tempo na localidade onde hoje está construída a Praça Morena Bela, o Colégio Estadual Rubem Nogueira e residências são frutos das articulações políticas daqueles que, com o voto da população, implementaram obras que contribuíram para que Serrinha, décadas depois, fosse classificada como urbana por atrair residências e pessoas para 0 centro, os quais perpassam pelos movimentos/tempos rápidos do processo de urbanização da cidade.

Percebe-se, também, que os agentes construtores da Praça Morena Bela, entendem-na como acessibilidade ilimitada, coletiva, aberta, podendo entrar, estar e sair na hora que bem desejarem. No entanto, uma de suas funções, além desta que se apresenta na paisagem, é a de favorecer o lazer e o entretenimento a população. Por mais que as pessoas se utilizem dessa praça, morar ou comprar uma casa em torno ou próxima a ela é somente um privilégio por parte daqueles que podem consumila. Basta às classes populares experimentarem uma idéia de acessibilidade cidadã.

Em outras palavras, a Praça Morena Bela é um espaço vivido, porque as pessoas incorporaram a Praça no seu cotidiano; e é um espaço percebido, a partir do momento em que os agentes sociais não se vêem isolados no espaço público, mas de modo coletivo, social; e pelo senso comum, pertencente a todos. É também um espaço produzido, devido ao modo como as pessoas usam o espaço produzindo e reproduzindo os seus valores, costumes e modos de relacionamento. E por último, é um espaço concebido porque cada pessoa tem uma visão subjetiva de como observa, entende e pensa a praça.

\section{Referências Bibliográficas}

CARLOS, A. F. A. O lugar no/do mundo. São Paulo: FFLCH, 2007, 85 p.

CASTRO, I. E. de C; GOMES, P. C. da C.; CORRÊA, R. L. (Orgs.). Geografia: Conceitos e temas. $7^{\text {a }}$ ed. Rio de Janeiro: Bertrand Brasil, 2005, 352p.

PRIBERAM. Dicionário online Priberam da Língua Portuguesa. Disponível em: $<$ http://www.priberam.pt/dlpo/dlpo.aspx> Acesso em jun. 2010

DUPAS, G. Tensões contemporâneas entre o público e privado. Cadernos de Pesquisa, v. 35, n. 124, p. 33-42, jan./abr. 2005. Disponível em: <http://www.scielo.br/pdf/\%0D/cp/v35n124/ a0335124.pdf> Acesso em: 01 jun. 2010.

FRANCO, T. Serrinha: A colonização portuguesa numa cidade do sertão da Bahia. Salvador: EGBA / Assembléia Legislativa do Estado. 1996.

FRANCO, T. Serrinha: A colonização portuguesa numa cidade do sertão da Bahia (A história do município de Serrinha). 2 ed. Salvador: EGBA / Assembléia Legislativa do Estado. 2008.

MACHADO, R. Cobrir para ver. Revista Discutindo Geografia. São Paulo: Igor Ribeiro, 2008. 4 ed. N. ${ }^{0} 20$.

NOGUEIRA, R. O Homem e o Muro (Memórias políticas e outras). São Paulo: Gumercindo Rocha Dorea (edições GRD). 1997. 415 p.

OLIVEIRA, M. P.; COELHO, M. C. N.; CORRÊA, A. de M. (ORGs.). O Brasil, América Latina e o mundo: espacialidades contemporâneas (II). Rio de Janeiro: Lamparina, FAPERJ, ANPEGE, 2008.

Geografia Ensino \& Pesquisa, v. 16, n.3 p. 49 - 62, set./dez. 2012

Nunes, F. S. 
PINHEIRO, D. M. N. A praça é do povo como o céu é do condor: violações ao direito à saúde na Praça Morena Bela Serrinha-BA. p. 58. Monografia (Especialização em Direito Sanitário) - Departamento de Saúde, Universidade Estadual de Feira de Santana - UEFS. Feira de Santana: 1999.

SANTOS, M. Metamorfose do espaço habitado: fundamentos teóricos e metodológicos da Geografia. 6 ed. São Paulo: EDUSP, 2008.

SCHIER, R. A. Trajetórias do conceito de paisagem na Geografia. R.RA'E GA, Curitiba: UFPR, no. 7, p. 79-85, 2003. Disponivel em: <http://ojs.c3sl.ufpr.br/ojs2/index.php/raega/article/ viewFile/3353/2689> Acesso em: 05 jun. 2010.

Espaço público e acessibilidade: notas para uma abordagem geográfica. Espaço e Tempo, GEOUSP - São Paulo, No 15, pp. 21 - 37, 2004. Disponível em: <www.geografia.fflch.usp. br/publicacoes/geousp/.../Artigo2.pdf> Acesso em 13 jun. 2010

SERPA, A. O espaço público na cidade contemporânea. São Paulo: Contexto, 2007. 205 p.

Espaço público: lócus da pluralidade humana? In: OLIVEIRA, Márcio Piñon de Oliveira. et. al. O Brasil, América Latina e o mundo: espacialidades contemporâneas (II). Rio de Janeiro: Lamparina, FAPERJ, Ampege, 2008. 448 p.

SERRINHA. Plano Diretor de Desenvolvimento Urbano de Serrinha. UFC Engenharia Ltda: 2003.

SPÓSITO, E. S. A vida nas cidades. 5a Ed. São Paulo: Contexto, 2004. 90 p.

\section{Correspondência:}

Fernando de Souza Nunes - Universidade do Estado da Bahia, Universidade do Estado da Bahia UNEB, Departamento de Educação Campus XI - Serrinha. Rua Alvaro Augusto s/n. Rodoviária. Cep. 48700000 - Serrinha, BA - Brasil

E-mail: fernandodsouzanunes@hotmail.com

Recebido em 14 de fevereiro de 2012.

Revisado pelo autor em 02 de setembro de 2012.

Aceito para publicação em 03 de setembro de 2012. 